Bangladesh Med Res Counc Bull 2018; 44:52-59

DOI: http://dx.doi.org/10.3329/bmrcb.v44i1.36805

\title{
Outcome of Surgical Induction of Labourin a Combined Military Hospital
}

\author{
Ara $\mathrm{I}^{1^{*}}$, Solaiman $\mathrm{SM}^{2}$, Hasan $\mathrm{MMS}^{2}$, Sultana $\mathrm{R}^{1}$ \\ ${ }^{1}$ Combined Military Hospital, Savar, Dhaka, Bangladesh \\ ${ }^{2}$ Army Headquarters, Dhaka Cantonment, Dhaka, Bangladesh
}

\begin{abstract}
Induction of labour is considered justified when the benefits of prompt delivery outweigh the consequences of Caeserian Section (CS). Literature on the effectiveness and safety of surgical induction of labour in term and postdated pregnancy is limited in Bangladesh. This study was aimed to assess the effectiveness and safety of surgical induction of labour in term and postdated pregnancy. This prospective clinical study was conducted in the in-patient Department of Obstetrics and Gynecology, Combined Military Hospital (CMH), Dhaka from July, 2005 to June 2006. A total of 100 pregnant women with term and postdated pregnancy were selected for the study by simple random sampling. The particulars of the patient, detailed menstrual and obstetric history, induction delivery interval, mode of delivery and foetal outcome and maternal complications were recorded. The results were analysed by Statistical Package for Social Science (SPSS) version 16.0.The mean \pm SD age of the participants was $25.79 \pm 6.16$ years with a range of $18-38$ years. The indication of Induction of labour included term pregnancy $(79 \%)$ and postdated pregnancy (21\%). Normal vaginal delivery was done in $78 \%$ cases, CS in $17 \%$ cases and vacuum extraction in 5\% cases.Ninety three percent babies were born healthy, $6 \%$ were asphyxiated, perinatal death $2 \%$ and still born $1 \%$. Oxygen inhalation was needed for $6 \%$ babies. Prolonged second stage (7\%), post-partum haemorrhage (8\%), maternal distress during labour $(10 \%)$ and manual removal of placenta (12\%) were the observed maternal complications. No significant difference was observed between term and post term pregnancy in term of normal vaginal delivery, vacuum extraction and lower uterine cesarean section. Induction of labour is beneficial for both term and postdated pregnancy with associated complications. Foetal outcome was good and maternal complications were acceptable.
\end{abstract}

Keywords: Surgical induction of labour, Post dated, Bishop's score Foetal outcome

\section{Introduction}

Induction of labour (IOL) is the stimulation of regular uterine contraction before the spontaneous onset of labour using mechanical or pharmacological methods in order to generate progressive cervical dilatation and subsequent delivery. ${ }^{1}$ For induction of labour, the benefits of early delivery to either mother or fetus should outweigh the risks of pregnancy continuation. ${ }^{2}$ The incidence of labour induction has continued to rise over the past several decades. ${ }^{3}$ The rate of labour induction varies from $9.5-33.7 \%$ of all pregnancies annually. ${ }^{4}$ Labour induction rates present a wide country variation and also present among obstetric units in the same geographic region or practitioners within the same hospital. This variability is the result of differences in the obstetric protocols or the judgment of the individual physician regarding the appropriateness of obstetric interventions. ${ }^{5}$ In developed countries, the number of infants delivered at term following induction of labour can be as high as one in four deliveries. ${ }^{6}$ The World Health Organization (WHO) Global Survey on Maternal and Perinatal Health, conducted in 24 countries which included nearly 3,00,000 observations, showed that $9.6 \%$ of them were delivered by labour induction. The survey found that African countries have lower rates of induction of labour (lowest: Niger 1.4\%) compared with Asian and Latin American countries (highest: Sri Lanka $35.5 \%){ }^{7}$ The rate of induction in Canada has increased steadily from $12.9 \%$ in 1991-1992 to $19.7 \%$ in 1999-2000. The rate reached a high of 
$23.7 \%$ in $2001-2002$, decreased slightly to $21.8 \%$ in 2004-2005, and since then remained steady. ${ }^{8}$

However, all inductions are not successful and some may develop complications. In nullipara with an unfavorable cervix undergoing labour induction, caesarean delivery rate is more than $30 \% .^{9}$ The increased risk of caesarean section after induced labour is well documented, but such obstetric intervention is considered justified when the benefits of prompt delivery outweigh the consequences of a caesarean section. Conditions such as postterm pregnancy, hypertensive disorders, intrauterine growth restriction and diabetes are commonly accepted indications for induction. ${ }^{2}$ The increased frequency of obstetric interventions, such as induction of labour, appears to have contributed to the current trends in caesarean rates ${ }^{10}$ It is associated with doubling in caesarean section delivery rate compared with spontaneous labour. ${ }^{11}$

However, there is evidence for an increase in the frequency of labour induction without any such agreed upon indication. This situation might lead to unnecessary caesarean deliveries and, consequently to a high risk of adverse outcomes for the mother and the child.$^{12}$ In the absence of a well-established clinical indication, the contribution of labour induction to caesarean rates among low-risk nulliparous women can approach 20\%. ${ }^{13}$ Additionally, labour induction in itself increases inhospital predelivery and labour time and costs beyond those that are related to surgery. ${ }^{14}$

Indications and contraindications for induction should be reviewed. Risks and benefits of labour induction should be discussed with the patient and relatives including the risk of cesarean delivery. Confirmation of gestational age is very important and fetal lung maturity status should be performed if indicated. ${ }^{2}$ Routine antenatal ultrasound for confirmation of expected date of delivery has been shown to reduce induction rates for post dates $(41+0$ weeks) pregnancies after correction of dates. ${ }^{15} \mathrm{~A}$ cervical examination should be performed and documented (Bishop score). Foetal presentation and position should be confirmed. Clinical pelvimetry should be performed and cephalopelvic disproportion (CPD) should be ruled out. According to WHO guidelines, labour induction should be performed at a center, where qualified staff and OT facilities are available for cesarean section. Uterine activity and electronic fetal monitoring (EFM) should be done for all patients undergoing labour induction. $^{2}$

Some of the methods of IOL are still used in current practices. Other methods such as vaginal or uterine douches, stimulant injections thrown into the rectum, and the use of ergot alkaloid have been abandoned because of their "ineffectiveness or poisonous effects on the infant" 16 Prostaglandins act on the cervix to enable ripening by a number of different mechanisms. Multiple other agents have been advocated for cervical ripening, use of Foley's catheter is a favoured method in low resource setups. ${ }^{17}$ Misoprostol is an effective agent for cervical ripening. ${ }^{1}$ Dinoprostone has been approved by FDA for cervical ripening in women at or near term with mean induction-delivery interval of $15.6+$ 0.7 hours. ${ }^{18}$ Surgical induction of labourcomprises artificial rupture of membrale (ARM) and stripping the membrane. These are the most commonly performed procedures in obstetrics for induction of labour.There is evidence that routine sweeping (stripping) of membranes promotes the onset of labour and that this simple technique decreases artificial rupture of membrale (ARM) rates. It is believed that the technique results in an increase of local production of prosglandins. ${ }^{19}$ Amniotomy can be a simple and effective component of labour induction when the membrane are accessible and the cervix is favourable. A 2007 cochrane meta-analysis of 17 trials with 2566 women measured the safety of amniotomy and intravenous oxytosin for induction of labour. Amniotomy alone resulted in fewer vaginal deliveries in 24 hours than amniotomy plus oxytocin. Amniotomy and oxytocin resulted in fewer instrumental deliveries than placebo. ${ }^{20}$

Although it is well documented that induction of labour increases the risk of caesarean, however such obstetric intervention is considered justified when the benefits of prompt delivery outweigh the consequences of a caesarean section. Conditions 
such as post-term pregnancy, hypertensive disorders, intrauterine growth restriction and diabetes are commonly indications of IOL. Literature on the effectiveness and safety of surgical induction of labour in term and post dated pregnancy is limited in Bangladesh. So, this study was undertaken to observe the effectiveness and safety of surgical induction of labour in term and post-dated pregnancy. The ultimate objective was to reduce the rate of caesarean section in term and post dated pregnancy, to avoid postmaturity and its consequences and to improve the foetomaternal outcome.

\section{Materials and methods}

This prospective clinical study was conducted in the inpatient Department of Obstetrics and Gynaecology, Combined Military Hospital (CMH), Dhaka for a period of 12 month from July, 2005.

A total of 100 pregnant women with uncomplicated term and postdated pregnancy with cephalic presentation who were admitted for delivery during July 2005 to June 2006, were selected for the study by simple random sampling. Patients should have regular antenatal checkup and could be multi or primi with regular menstrual cycle previously. Patients with preterm labour, multiple pregnancies and malpresentations were excluded.

On admission, the particulars of the patient, such as name, age, parity, detailed history of pregnancy, menstrual history with last menstrual period and obstetric history were recorded. Family history, past medical and obstetric history and drug history were also noted. Pregnancy was dated according to last normal missed periods (LNMP) and confirmed by early ultrasound scan. Studied variables were recorded including patients profile, obstetric, medical and surgical history and gestational age. A thorough general physical examination was done followed by local examination, which included per abdomen examination and per vaginal examination. The indication for IOL of each case was noted and the method of induction was chosen according to the individual case. Induction was performed according to the pre-defined criteria and details of labour were noted down. Mode of delivery and fetal outcome were recorded. Informed written consent was obtained from either the participants or their guardians. Ethical clearance was obtained from relevant authority. Data was recorded on a predesigned data collection sheet. The results were analyzed by Statistical Package for Social Science (SPSS) version 16.0. Relevant descriptive statistics, frequency and percentage were computed for qualitative data like mode of delivery, mode of induction and parity. Mean and standard deviation were computed for continuous variables like length of gestation in weeks, length of labour and Bishop score.

\section{Results}

The foetal and maternal outcome of 100 pregnant women who underwent surgical induction of labour was assessed.

Table I: Particulars of the patients

\begin{tabular}{lll}
\hline Particulars & & Frequency $(\%)$ \\
\hline Age (in years) & $\leq 20$ & $26(26 \%)$ \\
& $21-35$ & $72(72 \%)$ \\
Age (Mean $\pm S D)$ & 255 & $2(2 \%)$ \\
Range (years) & $18-38 \pm 6.16$ & \\
Gravidity state & & \\
& Primi & $51(51 \%)$ \\
Mucioeconomic condition & $49(49 \%)$ \\
& Lower & $17(17 \%)$ \\
& Middle & $69(69 \%)$ \\
& Upper & $14(14 \%)$ \\
Previous obstetric history & \\
& Normal vaginal delivery & $36(36 \%)$ \\
& Forceps delivery & $2(2 \%)$ \\
& Vacuum extraction & $1(1 \%)$ \\
& Abortion & $11(11 \%)$ \\
& MR & $9(9 \%)$ \\
& Perinatal death & $3(3 \%)$ \\
& Still born & $2(2 \%)$ \\
& IUD & $2(2 \%)$ \\
Pregnancy status & & \\
& Term pregnancy & $79(79 \%)$ \\
& Postdated pregnancy & $21(21 \%)$ \\
\hline
\end{tabular}

$\mathrm{f}=$ frequency

The mean \pm SD age of the participants was $25.79 \pm 6.16$ years with a range of 18-38 years. Almost three-quarters $(72 \%)$ of the patients were in age group 21-35 years, $26 \%$ were in age group $<20$ years and only $2 \%$ in age $>35$ years age group. Gravidity state of the participants were almost similar with primipara $51 \%$ and multipara $49 \%$. More than two-thirds (69\%) of the participants 
belonged to middle class, $17 \%$ belonged to lower class and $14 \%$ to upper class (table I).

Previous obstetric history of multipara participants included normal vaginal delivery (36\%), abortion (11\%), MR (9\%), perinatal death (3\%), forceps delivery (2\%), still born(2\%), IUD (2\%) and vacum extraction $(1 \%)$.

The indication of IOL included term pregnancy (79\%) and postdated pregnancy (21\%). Other associated conditions with term pregnancy were preeclampsia (7\%), hypertensive disorder (2\%), $\mathrm{Rh}$ incompatibility (2\%) and diabetes (6\%).

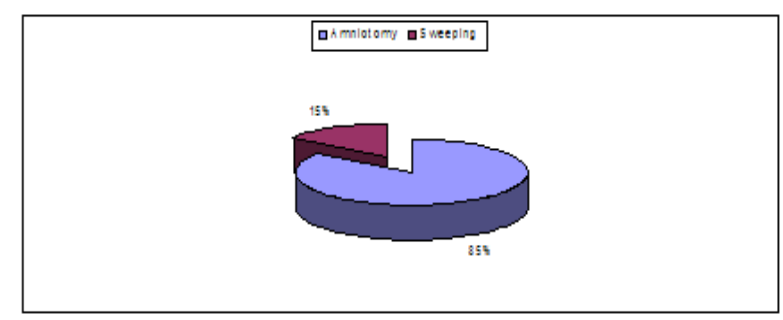

Figure1: Type of induction of labour

For induction of labour amniotomy was done in $85 \%$ cases and sweeping in 15\% cases (figure 2).

Table II: Mode of delivery and maternal details at amniotomy and sweeping

\begin{tabular}{|c|c|c|}
\hline Mode of delivery & cause of intervention & $\begin{array}{l}\text { Frequency } \\
(\%)\end{array}$ \\
\hline \multirow[t]{3}{*}{ Normal vaginal delivery } & & $78(78 \%)$ \\
\hline & with episiotomy & $62(62 \%)$ \\
\hline & without episiotomy & $16(16 \%)$ \\
\hline \multirow{4}{*}{ Vacuum extraction } & & $5(5 \%)$ \\
\hline & $\begin{array}{l}\text { prolonged } 2^{\text {nd }} \text { stage of labour } \\
\text { with maternal distress }\end{array}$ & $3(3 \%)$ \\
\hline & cord round the neck & $1(1 \%)$ \\
\hline & mal-rotation & $1(1 \%)$ \\
\hline \multicolumn{2}{|c|}{ Lower uterine cesarean section } & $17(17 \%)$ \\
\hline & $\begin{array}{l}\text { foetal distress (meconium stain } \\
\text { liquor) }\end{array}$ & $12(12 \%)$ \\
\hline & $\begin{array}{l}\text { cervical dystonia with foetal } \\
\text { distress }\end{array}$ & $1(1 \%)$ \\
\hline & $\begin{array}{l}\text { Occipito posterior with } \\
\text { prolonged } 1^{\text {st }} \text { stage }\end{array}$ & $2(2 \%)$ \\
\hline & $\begin{array}{l}\text { Deep transverse arrest with } \\
\text { prolonged } 1^{\text {st }} \text { stage }\end{array}$ & $2(2 \%)$ \\
\hline \multicolumn{3}{|l|}{ Maternal details } \\
\hline \multicolumn{3}{|l|}{ Engagement of head } \\
\hline & Engaged & $65(65 \%)$ \\
\hline & Non-engaged & $35(35 \%)$ \\
\hline \multicolumn{3}{|l|}{ Cervical dilatation } \\
\hline & $<2$ & $46(46 \%)$ \\
\hline & $2-4$ & $54(54 \%)$ \\
\hline & Mean \pm SD & $2.535 \pm 1.13$ \\
\hline \multicolumn{3}{|l|}{ Bishop's score } \\
\hline & $<5$ & $4(4 \%)$ \\
\hline & $\geq 5$ & $96(96 \%)$ \\
\hline \multicolumn{3}{|l|}{ Use of oxytocin } \\
\hline & with oxytocin & $33(33 \%)$ \\
\hline & without oxytocin & $67(67 \%)$ \\
\hline
\end{tabular}

$\mathrm{f}=$ frequency
Normal vaginal delivery was done in $78 \%$ cases: $62 \%$ with episiotomy and $16 \%$ without episiotomy. Vacuum extraction was done in 5\% cases: $3 \%$ due to prolonged $2^{\text {nd }}$ stage of labour with maternal distress, $1 \%$ due to cord round the neck and $1 \%$ due to malrotation. Lower uterine cesarean section was needed in $17 \%$ cases: $12 \%$ had foetal distress (meconium stain liquor), $1 \%$ had cervical dystonia with foetal distress, $2 \%$ had occipito posterior with prolonged $1^{\text {st }}$ stage and $2 \%$ had deep transverse arrest with prolonged $1^{\text {st }}$ stage (table II).

At time of amniotomy and sweeeping $65 \%$ of mothers had got engagement of the head of the fetus and $35 \%$ had not engaged. In $46 \%$ cases cervical dilatation was $<2$ and others (54\%) had 2-4 cervical dilatation. Bishop's score was $<5$ in $4 \%$ cases and $\geq 5$ in $96 \%$ cases. Oxytocin was used in $33 \%$ cases and not in $67 \%$ cases (table II). No significant difference was observed between term and post term pregnancy in the term of normal vaginal delivery $(p=0.553)$, vacuum extraction $(p=0.955)$ and lower uterine cesarean section $(p=0.514)$. Almost similar maternal conditions were observed in engagement of fetal head $(p=0.799)$, cervical dilatation $(p=0.809)$, Bishop's score $(p=0.841)$, and use of oxytocin $(p=0.109)$ between term and post term pregnancy (table II).

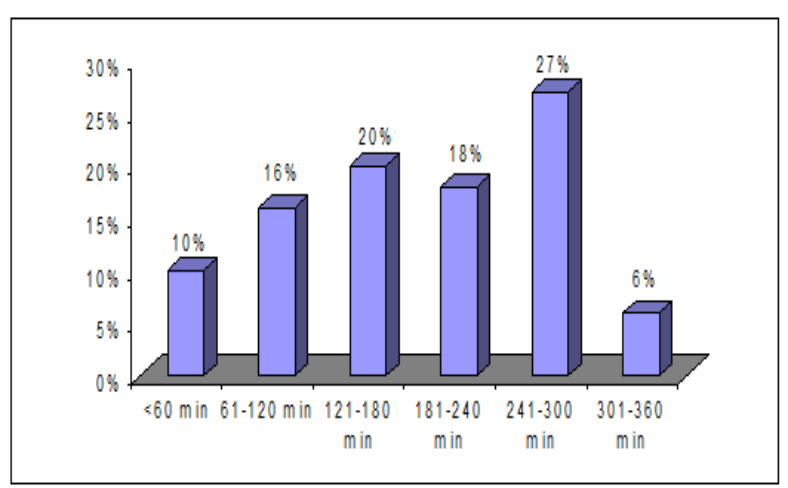

Figure 2: Amniotomy-delivery interval time (in minute)

The interval time between amniotomy-delivery were $<60$ minute in $10 \%$ participants with a mean \pm SD $51.2 \pm 10.6$ minutes, $61-120$ minutes in $16 \%$ cases with a mean \pm SD $94.1 \pm 13.8$ minutes, 121-180 minutes in $20 \%$ cases with a mean \pm SD $166 \pm 17.9$ 
minutes, $181-240$ minutes in $18 \%$ cases with a mean \pm SD 211.9 \pm 12.0 minutes, $241-300$ minutes in $18 \%$ cases with a mean \pm SD $211.9 \pm 12.0$ minutes, 301-360 minutes in 6\% cases with a mean \pm SD $343.3 \pm 13.7$ minutes (figure-2) $.93 \%$ baby was born healthy, $6 \%$ were asphyxiated, perinatal death and still born were $2 \%$ and $1 \%$ respectively. The mean \pm SD birth weight of the babies was $3.05 \pm 0.588$ $\mathrm{Kg}$ with $22 \%$ babies weigh $<2.5 \mathrm{Kg}, 77 \%$ weigh 2.5 $4 \mathrm{Kg}$ and $1 \%$ weigh $>4 \mathrm{Kg}$ (table-III).

Table III: Foetal outcome

\begin{tabular}{|c|c|c|c|c|}
\hline $\begin{array}{c}\text { Foetal } \\
\text { outcome }\end{array}$ & $\begin{array}{c}\text { Term } \\
\text { pregnancy } \\
(\mathbf{n}=79) \\
\mathbf{f}(\%)\end{array}$ & $\begin{array}{c}\text { Post term } \\
\text { pregnancy } \\
(\mathbf{n}=21) \\
\mathbf{f}(\%)\end{array}$ & $\begin{array}{l}\text { Total } \\
\mathbf{f}(\%)\end{array}$ & $\begin{array}{c}p \\
\text { value }\end{array}$ \\
\hline Healthy baby & $74(74 \%)$ & $19(19 \%)$ & $93(93 \%)$ & 0.635 \\
\hline Still born & $1(1 \%)$ & $0(0 \%)$ & $1(1 \%)$ & \\
\hline Asphyxiated & $3(3 \%)$ & $1(1 \%)$ & $4(6 \%)$ & \\
\hline $\begin{array}{l}\text { Perinatal } \\
\text { death }\end{array}$ & $1(1 \%)$ & $1(1 \%)$ & $2(2 \%)$ & \\
\hline \multicolumn{5}{|l|}{ Birth weight } \\
\hline$<2.5 \mathrm{~kg}$ & $19(19 \%)$ & $2(2 \%)$ & $22(22 \%)$ & 0.010 \\
\hline $2.5-4 \mathrm{~kg}$ & $60(60 \%)$ & $17(17 \%)$ & $77(77 \%)$ & \\
\hline$>4 \mathrm{~kg}$ & $0(0 \%)$ & $2(2 \%)$ & $1(1 \%)$ & \\
\hline Mean \pm SD & & & $3.05 \pm 0.588$ & \\
\hline \multicolumn{5}{|l|}{$\begin{array}{l}\text { Apgar score } \\
(1 \mathrm{~min})\end{array}$} \\
\hline$\leq 3$ & $1(1 \%)$ & $1(1 \%)$ & $2(2 \%)$ & 0.172 \\
\hline $4-6$ & $21(21 \%)$ & $2(2 \%)$ & $23(23 \%)$ & \\
\hline$\geq 7$ & $57(57 \%)$ & $18(18 \%)$ & $75(75 \%)$ & \\
\hline \multicolumn{5}{|l|}{$\begin{array}{l}\text { Apgar score } \\
(5 \mathrm{~min})\end{array}$} \\
\hline$\leq 3$ & $1(1 \%)$ & $1(1 \%)$ & $2(2 \%)$ & 0.198 \\
\hline $4-6$ & $2(2 \%)$ & $2(2 \%)$ & $4(4 \%)$ & \\
\hline$\geq 7$ & $76(76 \%)$ & $18(18 \%)$ & $94(94 \%)$ & \\
\hline Mean \pm SD & & & $7.52 \pm 1.51$ & \\
\hline
\end{tabular}

Three-quarters (75\%) babies had 1 min Apgar score $\geq 7,23 \%$ had $4-6$ and $2 \%$ had $\leq 3$. When 5 min-Apgar score was calculated, 95\% babies had Apgar score $\geq 7$, 4\% had 4-6 and $1 \%$ had $\leq 3$ (tableIII). The number babies with normal birth weight was significantly higher in post term pregnancy than term pregnancy $(p=0.010)$. No significant difference was observed between term and post term pregnancy in the term of birth of healthy babies $(p=0.635)$, Apgar score (1 min) $(p=0.172)$ and Apgar score (5 $\min )(p=0.198)$.
Table IV: Foetal and maternal complications

\begin{tabular}{ll}
\hline Foetal complication & \\
\hline No resuscitation needed & $94(94 \%)$ \\
Resuscitation needed & $6(6 \%)$ \\
$\mathrm{O}_{2}$ inhalation & \\
$\quad$ by nasal catherter & $4(4 \%)$ \\
$\quad$ bag mask by intubations & $2(2 \%)$ \\
Intrapartumfoetal distress & \\
$\quad$ i) Meconium staining & $12(12 \%)$ \\
$\quad$ ii) Cord around the neck & $2(2 \%)$ \\
Babies referred to neonatal care unit & $7(7 \%)$ \\
Asphyxia and low Apgar score & $2(2 \%)$ \\
Low birth weight & $12(12 \%)$ \\
Instrumental delivery & $5(5 \%)$ \\
Rh-incompatibility & $2(2 \%)$ \\
Admission & $2(2 \%)$ \\
Maternal complication & \\
Cervical dystocia & $1(1 \%)$ \\
Prolonged second stage & $7(7 \%)$ \\
Cervical tear & $3(3 \%)$ \\
Post-partum haemorrhage & $8(8 \%)$ \\
$\quad$ i) Uterine atony & $2(2 \%)$ \\
$\quad$ ii) Vaginal laceration & $3(3 \%)$ \\
$\quad$ iii) Cervical tear & $3(3 \%)$ \\
Manual removal of placenta & $12(12 \%)$ \\
Instrumental delivery & $1(1 \%)$ \\
Blood transfusion needed & $2(2 \%)$ \\
Maternal distress during labour & $10(10 \%)$ \\
\hline f= frequency &
\end{tabular}

No resuscitation was needed in $94 \%$ babies. $6 \%$ needed Oxygen inhalation: $4 \%$ by nasal catherter and $2 \%$ with bag mask by intubations. Intrapartum foetal distress was observed in $14 \%$ patients, $12 \%$ had meconium staining and $2 \%$ had cord around the neck. $7 \%$ babies referred to neonatal care unit, $2 \%$ had asphyxia and low Apgar score, 12\% had low birth weight and Rh- incompatibility was found in $2 \%$ cases. Instrumental delivery was needed in 5\% cases and $2 \%$ babies required admission (table-IV). Among the maternal complications, the common complications were prolonged second stage (7\%), post-partum haemorrhage (8\%), maternal distress during labour (10\%) and manual removal of placenta (12\%). the causes of post-partum haemorrhage included uterine atony (2\%), vaginal laceration (3\%) and cervical tear (3\%). Other less frequent complications were cervical dystocia (1\%), cervical tear (3\%), instrumental delivery $(1 \%)$ and blood transfusion (2\%). 


\section{Discussion}

Induction of labouris the artificial initiation of labour before its spontaneous onset of deliver the foetoplacental unit. The frequency of induction varies location and institution. When undertaken for appropriate reason, and by appropriate methods, induction is useful and benefits both mother and newborn. An ideal method of induction must be cost effective, must ensure efficacy and safety for the mother and the foetus with minimal induction delivery interval, and should be convenient for the patient and the medical staff. ${ }^{21}$ Induction is indicated when the risk of continuing the pregnancy, for the mother or the fetus, exceeds the risk associated with induction of labour and delivery. The management of labour determines to a great extent the outcome both for the mother and baby. ${ }^{22}$ Postdate induction is the leading indication for induction and deserves special consideration. The goal is the prevention of postterm pregnancy with its associated increased perinatal morbidity, mortality, operative delivery rates. ${ }^{23}$ In the process of labour, the foetal and maternal conditions are closely monitored to prevent or promptly identify any problem and threat. However, many practices in the modern labour have come under question recently. ${ }^{24}$ Amniotomy is believed to result in a shorter duration of labour by enhancing uterine contraction and also to reduce the incidence of dystocia. ${ }^{24}$ Results of this study showed that all patients delivered within 6 hours who underwent amniotomy (figure 2).

Study concluded that amniotomy significantly reduced the duration of labour especially in the first stage of labour without affecting oxytocin requirements. $^{25}$

Mikkinet al conducted a study on amniotomy in 533 multiparous women and 157 nulliparous women and randomized them to either amniotomy or intent to conserve membranes. Duration of labour was reduced in both nulliparous and multiparous patients in amniotomy group and oxytocin was used less in the intervention arm. ${ }^{26}$
Garite et al reported the reduction in duration of labour in addition with no difference in mode of delivery between the two groups.On the other hand, a study by Mechthild et al concluded that "the rupture of membranes shortened 1st stage of labour. This effect was larger than that of any other factor and more pronounced in multiparas.Studies observed that the oxytocin requirement for labour augmentation in the amniotomy group is slightly lower than for the control. This difference is likely to be due to the increased contractility of the uterus, which is said to result from better application of foetal head to the cervix following amniotomy in labour. Sega et al reported an increased incidence of foetal heart rate abnormality or foetal distress and thus cesarean section following amniotomy. ${ }^{29}$

In the present study, the indication of IOL included term pregnancy $(79 \%)$ and postdated pregnancy (21\%). Other associated conditions with term pregnancy were pre-eclampsia $(7 \%)$, hypertensive disorder (2\%), Rh incompatibility (2\%) and diabetes (6\%) (table I).Boulvain et al also reported these these conditions as the most common indications for IOL.

Out of the total, $78 \%$ of the patients delivered vaginally, vacuum extraction was done in $5 \%$ cases and $17 \%$ underwent cesarean section (table II), which is comparable to the study of Boulvain et al who reported vaginal delivery and cesarean in $87.88 \%$ and $12.12 \%$ of the patients, respectively. ${ }^{30}$

In this study, prolonged second stage of labour (7\%) and post-partum haemorrhage $(8 \%)$ were most common complications (tableIV). PPH and maternal pyrexia were the most common maternal complications observed and occurred in $5.66 \%$ and $2.36 \%$, respectively in the study by Boulvain et al, whereas the study by Tan et al reported PPH and maternal pyrexia in $13.3 \%$ and $21 \%$, respectively. ${ }^{30,31}$

\section{Conclusion}

The study observed that IOL is beneficial for both primipara and multipara women as well as term and postdated pregnancy with associated complications. After IOL delivery was done in the most of the cases 
by NVD. Foetal outcome was good. Maternal and foetal complications were acceptable. As surgical IOL is safe and effective, it should be used in proper indication to reduce the rate of caesarean section in term and postdated pregnancy, to avoid postmaturity and its consequences and to improve the fetomaternal outcome.

\section{References}

1. Diekel L SI. Induction of labour and pregnancy termination for fetal abnormality. In: James DK, Weiner CP, Steer PJ, Gonile B, editors. High risk pregnancy management.3rd. edn. Philadelphia: Elsevier;2006; 2.p. $1392-42$.

2. ACOG Committee on Practice Bulletins - Obstetrics. ACOG Practice Bulletin No. 107: Induction of labour. Obstet Gynecol. 2009;114(2 Pt 1):386-97.

3. WHO recommendations for induction of labour. World Health Organization: Geneva. 2011.

4. Tenore JI. Methods for cervical ripening and induction of labour. Am Fam Physician.2003; 67:2123-28.

5. Luthy DA, Malmgren JA, Zingheim RW: Cesarean delivery after elective induction in nulliparous women: the physician effect. Am J Obstet Gynecol. 2004, 191:1511-15.

6. Martin JA, Hamilton BE, Sutton PD, Ventura SJ, Menacker F, Kirmeyer S, et al; Centers for Disease Control and Prevention National Center for Health Statistics National Vital Statistics System. Births: final data for 2005. Natl Vital Stat Rep. 2007;56:1-103.

7. WHO Global Survey on Maternal and Perinatal Health. Induction of labour data. World Health Organization: Geneva; 2010.

8. Health Canada. Canadian perinatal Health Report,2008Ottawa: Government of Canada:2008 Available at: http:/wwwphaac.aspc,gc.ca/publicat 2008)

9. Johnson DP, Davis NR, Brown AJ. Risk of cesarean delivery after induction at term in nulliparous women with an unfavourable cervix. Am College ObstetGynecol. 2003;188:1565-69.

10. Simpson KR, Atterbury J: Trends and issues in labour induction in the United States: implications for clinical practice. J ObstetGynecol Neonatal Nurs 2003, 32:76779.

11. Tan PC, Valiapan SD, Tay PY, Omar SZ. Concurrent oxytocin with dinoprostonepessary versus dinoprostonepessary.Labour induction of nulliparous with unfavourable cervix; a randomized placebocontrolled trial.Br J ObstetGynaecol.2007; 114:821-32.

12. De Luca R, Boulvain M, Irion O, Berner M, Pfister RE: Incidence of early neonatal mortality and morbidity after late-preterm and term cesareandelivery. Pediatrics 2009, 123:e1064-e71.

13. Ehrenthal DB, Jiang X, Strobino DM: Labour induction and the risk of acesarean delivery among nulliparous women at term. ObstetGynecol2010, 116:35-42.

14. Henderson J, McCandlish R, Kumiega L, Petrou S: Systematic review of economic aspects of alternative modes of delivery. BJOG. 2001;108:149-157.

15. Neilson JP. Ultrasound for fetal assessment for in early pregnancy. Cochrane Database Syst Rev 1998;4:CD000182.

16. Thomas R. observations on the caesarean section and on other obstetrics complications. Manchester: Bradley's Library Oxford; 1865.

17. Arif N, Mushtaq M. A randomized comparision of Foley catheter insertion versus prostaglandin E2 vaginal pessary for induction of labour in postdate pregnancy. Pak Armed Forces Med J.2010; 60:104-8.

18. Valadan M, Niroomanesh S, Noori K, Khalilian S, Tehrani M. Comparison of dinoprostone plus oxytocin and oxytocin alone for induction of labour. ActaMedicaIranica2005; 43:259-62.

19. Takahashi T, Marcus B, Scheerer RG, Katz M. A new model for objective assessment of cervical reipening the effect of prostaglandin E2 and prelabour contractility. Am J ObstretGynnecol1991;164:1115-8). ${ }^{19}$

20. (Howarth GR, Botha DJ. Amniotomy plus intravenous oxytosin for induction of labour. Cochrane Database Syst Rev. 2001;3:CD003250.

21. Arulkumaran S, Gibb DM, Tambyraja RL, Heng SH, Ratnam SS. Failed induction of labour. Aust N Z J ObstetGynaecol.1985;25:190-93.

22. Whittle MJ.The management and monitoring of labour.In: Chamberlain G, eds. Turnbull's Obstetrics. 2nd ed. Edinburgh: Churchill Livingstone 1995: 569-80.

23. Hermus MA, Verhoeven CJ, Mol BW, de Wolf GS, Fiedeldeij CA. Comparison of induction of labour and expectant management in postterm pregnancy: a matched cohort study. J Midwifery Womens Health.2009; 54: 351-56.

24. Janes R. Rural hospital amniotomy induction for women at or past term with a healthy pregnancy and a favourable cervix: Is it a safe option? N Z Med J 2001; 114 111-13. 
25. Ajadi M A ,Kuti O, Orji E O . The effect of amniotomy on the outcome of spontaneous labour in uncomplicated pregnancy.J ObstetGynaecol 2006; 26: 631-34.

26. Mikki N, Abu Asab N, Abu- Rmeileh NM. A trial of amniotomy in a Palestinian hospital. J ObstetGynaecol. 2007; 27:368-73.

27. Garite TJ, Porto M, Carlson NJ, Rummey PJ. Influence of electiveamniotomy on fetal heart rate and the course of labour in term patients. Am J ObstetGynecol. 1993;168: 1827- 32 .

28. Mechthild M, GrossRM ,Drobni S, Marc JNC. Influence of fixed and time dependent factors on duration of normal first stage labour. Birth. 2005; 32: 27- 33.
29. Sega D, Sheiner E, Yohai D, Sholam- Verdi I.Earlyamniotomy high risk factor for caesarean section. Eu J ObstetGynaecolReprodBiol 1999; 86:145-49.

30. Boulvain M, Fraser WD, Marcoux S, Fontaine JY, BazinS,Pinautt JJ et al. Does sweeping of the membranes reduce the need for formal induction of labour? A randomizedcontrolled trial. $\mathrm{Br} \quad \mathrm{J}$ ObstetGynecol. 1998;105:34-40.

31. Tan PC, Valiapan SD, Tay PYS, Omar SZ. Concurrent oxytocin with dinoprostonepessary versus dinoprostonepessary in labour induction of multiparas with infavourable cervix: a randomized placebocontrolled trial. Br J ObstetGynae.2007;114:824-32.

*Correspondence: Ismat Ara, Gynaecologist and Obstetrician, Combined Military Hospital, Savar, Dhaka, Bangladesh email: ismatara893@yahoo.com 